Article

\title{
The Use of Big Data for Sustainable Development in Motor Production Line Issues
}

\author{
Yao-Chin Lin ${ }^{(}$, , Ching-Chuan Yeh, Wei-Hung Chen *, Wei-Chun Liu and Jyun-Jie Wang \\ Department of Information Management, Yuan Ze University, Taoyuan 32003, Taiwan; \\ imyclin@saturn.yzu.edu.tw (Y.-C.L.); s1049202@mail.yzu.edu.tw (C.-C.Y.); s1059203@mail.yzu.edu.tw (W.-C.L.); \\ s1086211@mail.yzu.edu.tw (J.-J.W.) \\ * Correspondence: wehchen123@gmail.com or s999202@mail.yzu.edu.tw
}

Received: 16 March 2020; Accepted: 25 June 2020; Published: 1 July 2020

\begin{abstract}
This study explores big data gathered from motor production lines to gain a better understanding of production line issues. Motor products from Solen Electric Company's motor production lines were used to predict failure points based on big data analytics, where 3606 datapoints from the company's testing equipment were statistically analyzed. The current study focused on secondary data and expert interview results to further define the relevant statistical dimensions. Only 14 of the original 88 detection parameters were required for monitoring the production line. The relationships between these parameters and the relevant motor components were established to indicate how an abnormal reading may be interpreted to quickly resolve an issue. Thus, a theoretical model for the monitoring of the motor production line was proposed. Further implications and practical suggestions are also offered to improve the production lines. This study explores big data analysis and smart manufacturing and demonstrates the promise of these technologies in improving production line efficiency and reducing waste to promote sustainable production goals. Big data thus constitute the core technology for advancing production lines into Industry 4.0 and promoting industry sustainability.
\end{abstract}

Keywords: motor production line; manufacturing; big data; Industry 4.0; life cycle prediction; process monitoring

\section{Introduction}

The Fourth Industrial Revolution, also referred to as Industry 4.0, has caused dramatic global changes. Automation and associated revolutionary technologies, including robotics, machine learning, and artificial intelligence, have affected almost every industry [1]. The advent of the Internet and e-commerce has led to rapid inter-connected development between our real and virtual worlds [2]. These advances have led to shifts in modern consumer patterns, and traditional industrial manufacturing models have gradually become unable to cope with this changing market environment. The concepts of Industry 4.0 and intelligent networking have thus become necessary.

A business that wishes to take advantage of Industry 4.0 must investigate horizontally integrated, vertically integrated, and networked manufacturing systems, which can be achieved using value-added networks combined with end-to-end digital integration across the entire value chain [3]. One of the largest components required to make Industry 4.0 implementations successful is the collection of large amounts of data for analysis. To address big data analytics for manufacturing, IBM presented five major application models according to the various problems and product lifecycles typically encountered in the manufacturing industry [4]. These models include material quality monitoring, equipment abnormality monitoring and prediction, life cycle prediction, process monitoring for early warning, and good rate warranty analysis. The application potential of big data in traditional manufacturing is 
vast [5]. Big data applications may be used to sense and predict market demand, improve product and service design, improve product quality and output, optimize workshop logistics, and control and reduce energy consumption. Furthermore, one may develop predictive maintenance and spare-part services to accurately predict the remaining life of equipment and optimize recovery decisions, which can reduce the environmental impact of the manufacturing industry [6,7]. Furthermore, safety information technology can be applied to the intelligent security management in various industries [8].

Overall, previous studies have demonstrated that many internal and external issues in the manufacturing processes of factories can be solved using big data analysis. Taiwanese companies are seeking to improve the application of big data analysis in their manufacturing of motors. However, there is no perfect template for this implementation. A small number of manufacturers have adopted advanced technologies; however, they are still operating these technologies manually. These shortcomings may be addressed by the solutions presented in foreign research studies. The present study aims to explore the potential big data solutions for Taiwanese enterprises, with a focus on the manufacturing of motors. Specifically, this study aims to assist the Solen Electric Company's introduction of big data analysis technology into their motor manufacturing process. Sensor data generated by the machinery and motor products can be monitored at any point in the manufacturing process, which allows a production line manager to evaluate and address problems as soon as they arise. The occurrence and accumulation of secondary products should be prevented to avoid unnecessary costs and increase smooth production operations; this can be achieved using big data analysis technology. Once successfully implemented, this technology can be extended to other intelligent manufacturing equipment applications in smart factories of varying natures and scales. The preliminary research results presented in a draft research report from the Taiwan Ministry of Science and Technology were also considered (published in Processes 2020, 8 (5), 537). The use of big data technology can help directly track each product, facilitate real-time monitoring, increase customer satisfaction, and ultimately improve a company's competitive advantage. These are the ideal results of applying big data to Industry 4.0.

The first research goal was to identify the test parameters that will be assessed and monitored using motor testing equipment, and establish a meaningful way to analyze and interpret these parameters. Motor testing equipment was used to test the status of motor products, and the results were stored in a database, including the test date, motor batch number, and 88 test motor performance parameters. The second research goal was to establish a statistical analysis approach for predicting which process in the motor production line is causing a problem. Linear regression was chosen for the statistical analysis, where the relationship between the number of rotations or current and many other factors was investigated and confirmed. If successful, these statistical models can be used to predict problems in the motor production process. Finally, the above research results are discussed with the UN Sustainable Development Indicators to explore the contribution of big data analysis and intelligent manufacturing to sustainable development.

Data were collected using motor test equipment at the factory under investigation, interviews with practical experts were conducted, and secondary data, provided by the company, were collected. To identify the parameters that could lead to useful information, hypotheses for the relationship between the parameters and various negative outcomes were evaluated. Finally, the corresponding production line process was evaluated to recommend improvements. Recommendations for future research and the application of data analysis in production lines were also proposed. The research process is shown in Figure 1. 


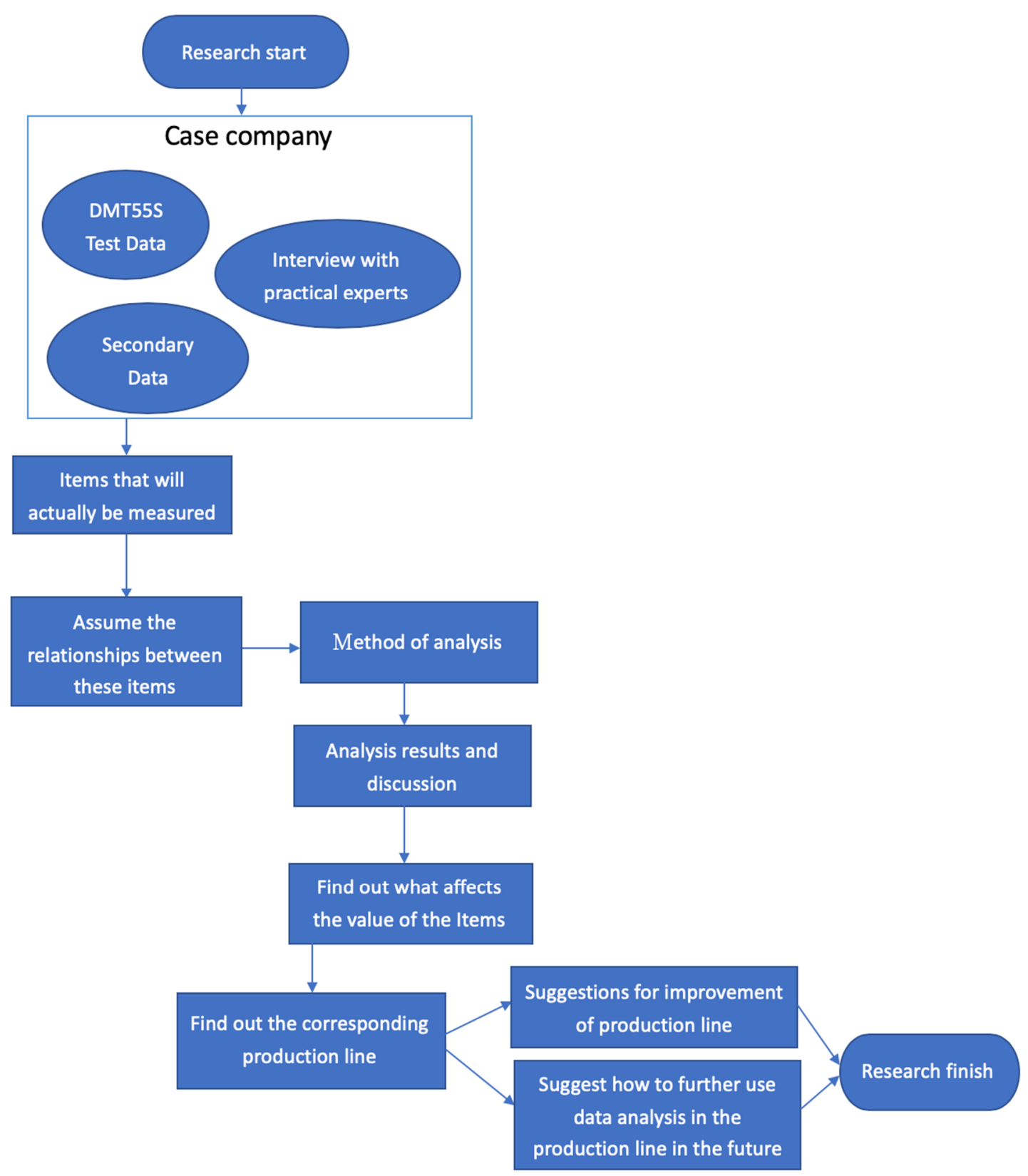

Figure 1. The overall research process of this study.

\section{Literature Review}

\subsection{Smart Manufacturing and Motor Production Lines}

Smart manufacturing is a strategy mainly based on the digitization of manufacturing-related activities and the rapid conversion of data into information [9]. Innovations in big data analysis can be used to support the fast data drive that facilitates today's turbulent decision-making processes. Combining business, resources, and functional objectives with industrial big data analytics in a smart factory allows for automated mining, tracking, optimization, and prediction [3].

The concept of Industry 4.0 utilizes technologies to support big data, extended real applications, and develop robotics and cyber physical systems [10]. Smart factories are an ideal that many manufacturers are striving to achieve in the near future [11]. Smart factories comprise integrated technologies, equipment, and processes for self-sufficient production models, and allow for decentralized decision-making with minimal human intervention [12]. These data may be transmitted and combined 
between the real and virtual worlds via a cyberspace physical system and the Internet of Things (IoT) [11]. This cyberspace physical system is a virtual simulation of the physical robots, process control systems, and other items that are integrated with the operations, physical processes, and environment [13]. IoT systems serve as sensors for automated equipment to connect to the network and expand the equipment's capabilities [14].

There are a few ways that smart factories can increase their productivity. These systems can gather and store a wide range of information from raw automation data. An earlier study investigated the manufacturing of power equipment circuit breakers [3]. The equipment operation status monitoring system monitored the energy consumption between water, electricity, and gas in a physical manufacturing space, and transmitted that information to virtual space. This method can be used to develop a production plan for energy management and scheduling.

Product quality may also be improved in a smart factory [15]. The plastic ball grid array printed circuit board manufacturing process is based on an association rule for the detection of a single accumulation factor, analyzing the process, equipment, and manufacturing yield to identify ways in which the production line yield may be improved. These advances will gradually improve the competitiveness of enterprises and reduce costs [16]. An Indian automotive manufacturing company implemented supervisory control and data collection and a commercial SAP recording system to identify alternative measures to reduce manufacturing costs, raw material usage, labor expenses, and manufacturing conversion costs.

The demand for saving energy has driven more intelligent motor production. In 2019, the parameters monitored during motor production were collected and analyzed by various devices with web browsers. The big data system's front end requires various sensors to obtain basic data. The sensor network formed between numerous sensors is based on continuously improving data transmission, where security is a priority to ensure a safe operating mode [17]. A previous study developed a data acquisition system based on a Hall effect sensor placed in the center of a coil to monitor and record the coil voltage and central magnetic field [18]. The raw data were transmitted wirelessly to monitor the aging of the equipment and to detect any uneven air gaps that could lead to decreased efficiency if not manually maintained by factory personnel. All data comparisons can be analyzed in the back end to verify and improve the structure and motor materials. An earlier study performed in situ monitoring, where the motor winding temperatures were verified to ensure that a short-circuit fault in the initial stator could be detected [19]. Fixed parameter standards were determined and used to ensure the efficient manufacturing of the motors.

\subsection{Big Data}

The big data used in the current study comprise test data collected from a motor production line, including 50,000 to 80,000 datapoints per month from actual observations. The company's motor production line has an average daily output of 1500-2000 pieces, and each motor has 14 important key parameters that are fully recorded. The latest information provided by Solen Electric Company on 30 April 2020 indicates that nearly 8 hundred thousand records are generated every month. When extrapolated, this number indicates that over 10 million records can be accumulated in one year, and hundreds of thousands of datapoints are accumulated over time. Big data analysis is extremely important in the basic operating of all technologies, particularly in the integration between technologies [20]. These systems can facilitate the improvement of manufacturing service quality or the execution of business decisions. The data eco-system of manufacturing services may be divided into the amount of internal and external data available to the enterprise [21]. Intelligent maintenance relies on the acquisition of high-quality data, which are analyzed internally and externally to drive efficient maintenance decisions [22]. Internal data are generated by sources within the manufacturing enterprise, for example, from manufacturing equipment, automation systems, artifacts, and enterprise information management. A data-driven culture can provide companies with information generated by environmental scans to develop more meaningful new products [23]. External data are environmental 
data accumulated from the external sources of a company, such as supply networks, governments (e.g., legislation and incentive programs), strategic partners, distribution channels, and customers. Managers should be proficient in using big data technology to analyze market trends, customer preferences, and product characteristics to support the system's decision-making, and to ensure service quality [24]. These optimized systems may aid managers through systematic analyses of data for yield management, product re-engineering, and predictive maintenance [9]. Big data analytics can also be used to optimize knowledge extraction and decision sharing for inventory and supply management [10].

The electrical and mechanical parameters of a motor (e.g., the current, power, and torque speed) can thus be modelled $[25,26]$. Time evolution is an important factor for maintaining fast and accurate models to monitor the status of induction motors. These models are used in expert systems to self-train, monitor, and identify system faults. Big data analysis and prediction have been applied to the production of electric motors. Table 1 summarizes these motor production studies and practical implementation cases for 48 test parameters. These parameters have upper and lower limits defined by their prescribed standard ranges. The values were recorded during testing and summarized. For example, No1 is the upper limit of no-load rotations and No2 is the upper limit of no-load rotations, while the no-load rotation merged into No1 counts as one item. 
Table 1. Summary of 48 motor testing parameters investigated in earlier studies.

\begin{tabular}{|c|c|c|c|c|c|c|c|c|}
\hline $\begin{array}{ll} & \text { Literature Project } \\
48 \text { Tests } & \end{array}$ & $\begin{array}{l}\text { Housing and Rotor } \\
\text { Cage Production }\end{array}$ & $\begin{array}{l}\text { Laminated Core } \\
\text { Production }\end{array}$ & $\begin{array}{l}\text { Insulation and } \\
\text { Impregnation }\end{array}$ & Winding & Contacting & $\begin{array}{c}\text { Shaft } \\
\text { Production }\end{array}$ & $\begin{array}{l}\text { Permanent Magnet } \\
\text { Rotor Production }\end{array}$ & $\begin{array}{l}\text { Final Assembly } \\
\text { and Testing }\end{array}$ \\
\hline No1 No-load rotation & $\bullet$ & & $\bullet$ & $\bullet$ & & $\bullet$ & $\bullet$ & $\bullet$ \\
\hline No3 No load current & $\bullet$ & & $\bullet$ & $\bullet$ & & $\bullet$ & $\bullet$ & $\bullet$ \\
\hline No5 Numbers of fixed-load rotations & $\bullet$ & & $\bullet$ & $\bullet$ & & $\bullet$ & $\bullet$ & $\bullet$ \\
\hline No7 Rated load current & $\bullet$ & & $\bullet$ & $\bullet$ & & $\bullet$ & $\bullet$ & $\bullet$ \\
\hline No9 Starting current & $\bullet$ & & $\bullet$ & $\bullet$ & & $\bullet$ & $\bullet$ & $\bullet$ \\
\hline No11 Starting torque & $\bullet$ & & $\bullet$ & $\bullet$ & & $\bullet$ & $\bullet$ & $\bullet$ \\
\hline No13 Torque constant & $\bullet$ & & $\bullet$ & $\bullet$ & & $\bullet$ & $\bullet$ & $\bullet$ \\
\hline No15 Torque loss & $\bullet$ & $\bullet$ & $\bullet$ & $\bullet$ & & $\bullet$ & $\bullet$ & $\bullet$ \\
\hline No17 TouchR & & & & & $\bullet$ & & & $\bullet$ \\
\hline No31 Ripple & & & $\bullet$ & $\bullet$ & $\bullet$ & & & $\bullet$ \\
\hline No32 IoUnst & & & $\bullet$ & $\bullet$ & $\bullet$ & & & $\bullet$ \\
\hline No33 SurgeV & & & $\bullet$ & $\bullet$ & $\bullet$ & & & $\bullet$ \\
\hline No34 Deat $P$ & & & $\bullet$ & $\bullet$ & $\bullet$ & & & $\bullet$ \\
\hline No35 Vibration & & & $\bullet$ & $\bullet$ & $\bullet$ & & & $\bullet$ \\
\hline No36 StartV & & & $\bullet$ & $\bullet$ & $\bullet$ & & $\bullet$ & $\bullet$ \\
\hline No37 Io Wave & & & $\bullet$ & $\bullet$ & $\bullet$ & & $\bullet$ & $\bullet$ \\
\hline No38 CoilR & & & $\bullet$ & $\bullet$ & & & & $\bullet$ \\
\hline No40 LoV Ripple & $\bullet$ & $\bullet$ & & & & $\bullet$ & $\bullet$ & $\bullet$ \\
\hline No81 Mg N/S & & & & & & & $\bullet$ & $\bullet$ \\
\hline No82 InsuV & & & $\bullet$ & $\bullet$ & & & & $\bullet$ \\
\hline No83 Cut & & & $\bullet$ & $\bullet$ & $\bullet$ & & & $\bullet$ \\
\hline No84 Open & & & $\bullet$ & $\bullet$ & $\bullet$ & & & $\bullet$ \\
\hline No85 Short & & & $\bullet$ & $\bullet$ & $\bullet$ & & & $\bullet$ \\
\hline No86 Lock & $\bullet$ & $\bullet$ & & & & $\bullet$ & $\bullet$ & $\bullet$ \\
\hline No87 No Mg & & & & & & & $\bullet$ & - \\
\hline No88 HandR & $\bullet$ & $\bullet$ & & & & $\bullet$ & $\bullet$ & $\bullet$ \\
\hline
\end{tabular}




\section{Methodology}

A statistical analysis was conducted on motor production line data generated using motor testing equipment (DMT55S) between 30 August 2018 and 3 June 2019. A total of 3606 motor test datapoints were collected.

\subsection{Research Framework}

Increased motor rotations per minute led to a faster rotation speed, causing increased chatter vibrations that can lead to higher current fluctuations. Therefore, the number of no-load and fixed-load rotations was positively correlated to vibrations and, in turn, current fluctuation.

James Watt defined the rate of energy conversion and use, where the amount of electrical energy converted to heat and light energy can be expressed as power (power $=\mathrm{n} \times$ torque $\times$ speed, speed and torque). There is a negative correlation between power and torque, while the speed and number of rotations are directly proportional. Therefore, the number of no-load and fixed-load rotations is inversely related to torque loss. Ohm's law defines the relationship between current $(\mathrm{I})$, voltage $(\mathrm{V})$, and resistance $(R)$ as $V=I \times R$, where current is proportional to voltage and inversely proportional to resistance. Therefore, the no load, fixed load, and start-up currents are proportional to surge voltage and inversely proportional to coil resistance.

\subsection{Hypotheses}

The architecture of this study was divided into two cases-the number of rotations and current (Figure 2)—and several hypotheses were proposed based on theoretical relationships.

\section{Case 1}

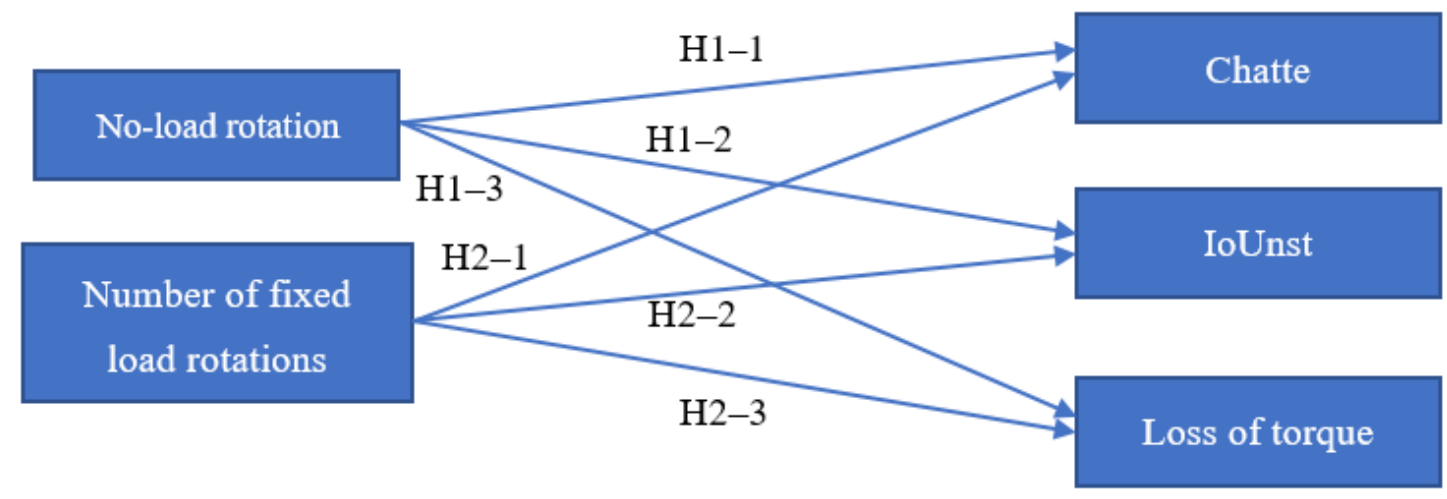

\section{Case 2}

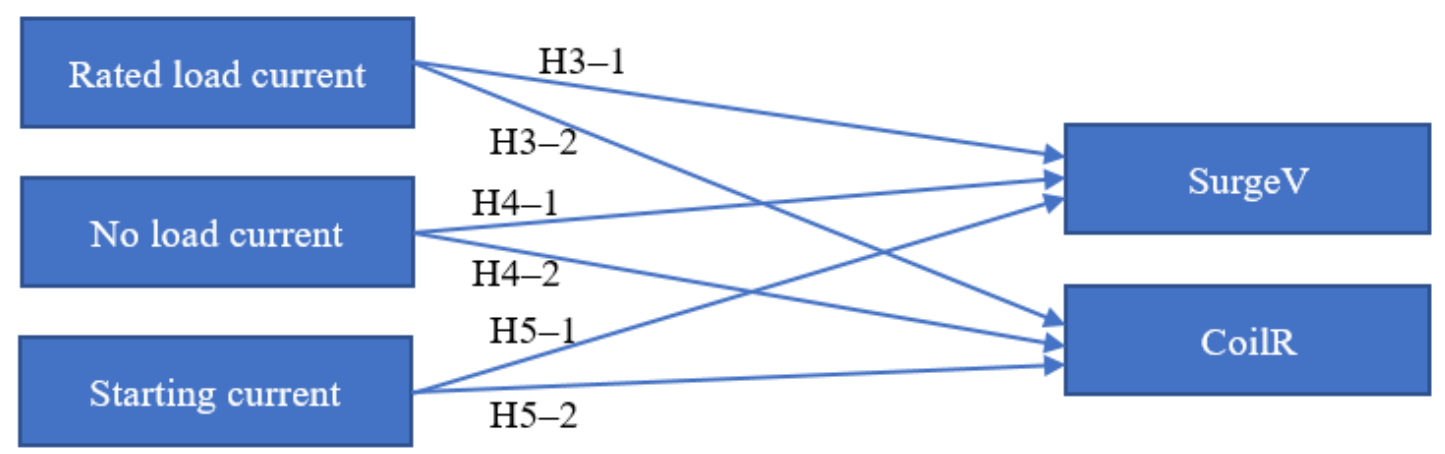

Figure 2. Research framework, which was divided into two cases with a total of 17 hypotheses.

Case 1: The effect of the number of rotations on vibration, current fluctuation, and torque loss. 
H1. The effect of the number of no-load rotations on vibration, current fluctuation, and torque loss.

H1-1. The number of no-load rotations is positively correlated with vibration.

H1-2. The number of no-load rotations is positively correlated with the current fluctuation.

H1-3. The number of no-load rotations is inversely correlated to torque loss.

H2. The effect of the number of fixed-load rotations on vibration, current fluctuation, and torque loss.

H2-1. The number of fixed-load rotations is positively related to vibration.

H2-2. The number of fixed-load rotations is positively correlated to the current fluctuation.

H2-3. The number of fixed-load rotations is inversely correlated to torque loss.

Case 2: The effect of current on surge voltage and coil resistance.

H3. The no-load current affects surge voltage and coil resistance.

H3-1. The no-load current is positively correlated to surge voltage.

H3-2. The no-load current is inversely correlated to coil resistance.

H4. The fixed-load current affects surge voltage and coil resistance.

H4-1. The fixed-load current is positively correlated to surge voltage.

H4-2. The fixed-load current is inversely correlated with coil resistance.

H5. The starting current affects surge voltage and coil resistance.

H5-1. The starting current is positively correlated to surge voltage.

H5-2. The starting current is inversely correlated to coil resistance.

\subsection{Instrumentation and Data Analysis}

Linear regression has been rigorously studied and widely used in practical applications because it makes models that are linearly dependent on their unknown parameters easier to deduce; it also makes the statistical properties of the estimates produced easier to determine. Linear regression was applied in this study, to determine and verify the relationships between the number of rotations or current and the independent and dependent variables of the other parameters. The SPSS 20.0 software package (IBM) was used to analyze 3606 motor test datapoints that were acquired using motor testing equipment (DMT55S). Hypothetical independent and dependent variables were analyzed during the data analysis to facilitate a more robust discussion of the results. The previously established (Table 1) data items from the 48 parameters were also measured and discussed (see Tables 2 and 3). 
Table 2. The original 48 measurement parameters.

\begin{tabular}{|c|c|c|}
\hline No. & Abbreviation & Short Description \\
\hline 1 & No Max & No-load rotation Max \\
\hline 2 & No Min & No-load rotation Min \\
\hline 3 & IO Max & No load current Max \\
\hline 4 & IO Min & No load current Min \\
\hline 5 & Nr Max & Rated load rotation Max \\
\hline 6 & Nr Min & Rated load rotations Min \\
\hline 7 & RI Max & Rated load current Max \\
\hline 8 & RI Min & Rated load current Min \\
\hline 9 & Is Max & Starting current Max \\
\hline 10 & Is Min & Starting current Min \\
\hline 11 & Ts Max & Starting torque Max \\
\hline 12 & Ts Min & Starting torque Min \\
\hline 13 & Kt Max & Torque constant Max \\
\hline 14 & Kt Min & Torque constant Min \\
\hline 15 & To Max & Torque loss Max \\
\hline 16 & To Min & Torque loss Min \\
\hline 17 & TouchR Max & Brush contact resistance Max \\
\hline 18 & TouchR Min & Brush contact resistance Min \\
\hline 31 & Ripple & Torque ripple \\
\hline 32 & IoUnst & Wave motion \\
\hline 33 & SurgeV & Surge voltage \\
\hline 34 & Deat P & Deat $\mathrm{P}$ \\
\hline 35 & Vibration & Flutter \\
\hline 36 & StartV & Starting voltage \\
\hline 37 & IoWave & Current waveform \\
\hline 38 & CoilR Max & CoilR Max \\
\hline 39 & CoilR Min & CoilR Min \\
\hline 40 & LoV Ripple Max & Low-voltage ripple Max \\
\hline 81 & $\mathrm{Mg} \mathrm{N} / \mathrm{S}$ & Magnet N pole/S pole \\
\hline 82 & InsuV & Insulation voltage \\
\hline 83 & Cut & Disconnected \\
\hline 84 & Open & Open Circuit Continuity \\
\hline 85 & Short & Short Circuit \\
\hline 86 & Lock & Lock \\
\hline 87 & $\mathrm{No} \mathrm{Mg}$ & No Magnet \\
\hline 88 & HandR & Manual rotation direction \\
\hline
\end{tabular}

Table 3. The fourteen test parameters selected for review.

\begin{tabular}{ccc}
\hline New No. & Abbreviation & Short Description \\
\hline 1 & No & No-load rotation \\
2 & $\mathrm{IO}$ & No load current \\
3 & $\mathrm{Nr}$ & Rated load rotations \\
4 & $\mathrm{RI}$ & Rated load current \\
5 & $\mathrm{Is}$ & Starting current \\
6 & $\mathrm{Ts}$ & Starting torque \\
7 & $\mathrm{Kt}$ & Torque constant \\
8 & To & Torque loss \\
9 & TouchR & Brush contact resistance \\
10 & IoUnst & wave motion \\
11 & SurgeV & Surge voltage \\
12 & Vibration & Flutter \\
13 & StartV & Starting voltage \\
14 & InsuV & Insulation voltage \\
\hline
\end{tabular}


A descriptive analysis of the samples (Table 4) revealed that the average value of each parameter was within the standard values stipulated by the company (Table 5). For example, the average no-load rotation value is 5059.94, which is within the stipulated range of 4335 to 5865 , thus indicating that the average motor was considered to be normal during production. However, this assumes that the human operator set the values correctly at the beginning of production. The original measurement parameters 1-15 were manually entered by the human operator before production of the motor, while parameters 17-82 were assessed after production was complete. However, the brush contact resistance (Touch R; parameter 17) was blank in most data, and the starting voltage (StartV; parameter 36) and insulation resistance (InsuV; parameter 82) were simply marked as "OK" for every sample, to indicate that the test result was normal with no failures. Therefore, these three variables were not included in the analysis.

Table 4. Statistical analysis of the 14 key parameters measured using the test equipment.

\begin{tabular}{|c|c|c|c|c|c|}
\hline & $\begin{array}{c}\text { Number of Test } \\
\text { Data Points }\end{array}$ & $\begin{array}{l}\text { Minimum } \\
\text { Value }\end{array}$ & $\begin{array}{l}\text { Maximum } \\
\text { Value }\end{array}$ & $\begin{array}{l}\text { Average } \\
\text { Value }\end{array}$ & $\begin{array}{c}\text { Standard } \\
\text { Deviation Value }\end{array}$ \\
\hline No-load rotation (r/min) & 3606 & 4891 & 5435 & 5059.94 & 66.642 \\
\hline No-load current $(\mathrm{mA})$ & 3606 & 93 & 165 & 114.46 & 11.814 \\
\hline Number of fixed-load rotations (r/min) & 3606 & 3876 & 4422 & 4144.91 & 102.712 \\
\hline Rated-load current (mA) & 3606 & 453 & 535 & 480.26 & 14.156 \\
\hline Starting current (mA) & 3606 & 1800 & 2689 & 2150.23 & 168.588 \\
\hline Starting torque (mNm) & 3606 & 36 & 56 & 43.68 & 3.498 \\
\hline Torque constant (mNm/A) & 3606 & 2 & 4 & 2.27 & 0.445 \\
\hline Torque loss $(\mathrm{mNm})$ & 3606 & 20 & 22 & 21.58 & 0.500 \\
\hline Ripple $(\Omega)$ & 3606 & 173 & 332 & 209.14 & 13.049 \\
\hline IoUnst (mA) & 3606 & 0 & 36 & 1.71 & 2.824 \\
\hline SurgeV (V) & 3606 & 22 & 64 & 24.87 & 1.560 \\
\hline Vibration (usce) & 3606 & 0 & 1296 & 236.82 & 374.083 \\
\hline CoilR $(\mathrm{ms} / 1)$ & 3606 & 4 & 7 & 5.55 & 0.580 \\
\hline Effective N (excluded completely) & 3606 & & & & \\
\hline
\end{tabular}

Table 5. Prescribed upper and lower limits of the 14 key parameters.

\begin{tabular}{ccc}
\hline New No. & Motor Test Machine Items & Normal Production Range \\
\hline 1 & No-load rotation & $4335-5865 \mathrm{r} / \mathrm{min}$ \\
2 & No-load current & $77.0-150.0 \mathrm{~mA}$ \\
3 & Number of fixed-load rotations & $3870-4730 \mathrm{r} / \mathrm{min}$ \\
4 & Fixed-load current & $329-611 \mathrm{~mA}$ \\
5 & Starting current & $1800-2880 \mathrm{~mA}$ \\
6 & Starting torque & $35.7-60.0 \mathrm{mNm}$ \\
7 & Torque constant & $20.0-22.0 \mathrm{mNm} / \mathrm{A}$ \\
8 & Torque loss & $0.0-5.0 \mathrm{mNm}$ \\
9 & Brush contact resistance & $0.0-1.0 \Omega$ \\
10 & Current fluctuation & Max: $3 \mathrm{~mA}$ \\
11 & Surge voltage & Max: $45.0 \mathrm{~V}$ \\
12 & Vibration & Max: $1300 \mathrm{usce}$ \\
13 & Starting voltage & $3.00 \mathrm{~V} 100 \mathrm{~ms} / 1$ \\
14 & Insulation resistance & DC $100 \mathrm{~V} 1 \mathrm{M} \Omega / \%$ up \\
\hline
\end{tabular}

The data exploration tool used in this research was Waikato Environment for Knowledge Analysis (WEKA), which is a software application developed by the University of Waikato in New Zealand that provides many different types of machine learning algorithms. For each problem to be solved, we chose the most appropriate algorithm. We confirmed that $66 \%$ of the training data was consistent for each variable [27] and suitable for deep learning using linear regression.

The results using WEKA's M5P algorithm and scheme (weka.classifiers.functions.LinearRegression-S 0-R 1.0E-8-num-decimal-places 4, in Test mode: split 66.0\% train, remainder test, after machine learning) are shown in Table 6. 
Table 6. WEKA linear regression results.

\begin{tabular}{ccc}
\hline No. & Item & Value \\
\hline 1 & No-load revolution speed & 0.8231 \\
2 & No load current & 0.9963 \\
3 & Fixed load rotation speed & 0.9981 \\
4 & Rated load current & 0.9969 \\
5 & Starting current & 0.9984 \\
6 & Starting torque & 0.9964 \\
7 & Torque constant & 0.8036 \\
8 & Torque loss & 0.8243 \\
9 & Ripple failed & 0.6237 \\
10 & Current fluctuation & 0.5768 \\
11 & Surge voltage volts & 0.1962 \\
12 & Vibration seconds & 0.693 \\
13 & Coil resistance & 0.8794 \\
\hline
\end{tabular}

In summary, the values from 0.7 to 0.99 are highly correlated, the values from 0.4 to 0.69 are moderately correlated, and the values from 0.1 to 0.39 are modestly correlated. Therefore, while many of the study variables were highly correlated, current fluctuation and chatter vibration seconds were only moderately correlated, and surge voltage volts were modestly correlated.

\section{Results}

The preliminary research results identified the parts contributing to the abnormal key parameter values. Some of the more specialized motor components (e.g., the rotor core) were related to torque loss and could be used to determine an affected part. The surge voltage, vibration, and start-up voltage values were also used to identify affected parts. The parameters that were monitored, as well as their related motor components, are listed in Table 7. 
Table 7. Motor components associated with each of the 15 key parameters.

\begin{tabular}{|c|c|c|c|c|c|c|c|c|c|c|c|c|}
\hline \multicolumn{3}{|c|}{ Items } & \multicolumn{10}{|c|}{ Parts That Can Be Affected } \\
\hline New No. & Abbreviation & Name & Coil & $\begin{array}{l}\text { Iron } \\
\text { Frame }\end{array}$ & $\begin{array}{c}\text { Iron } \\
\text { Frame Lid }\end{array}$ & Magnet & $\begin{array}{c}\text { Brush } \\
\text { Assembly }\end{array}$ & Bearing & $\begin{array}{l}\text { Rotor } \\
\text { Core }\end{array}$ & $\begin{array}{l}\text { Terminal } \\
\text { Assembly }\end{array}$ & Brush & $\begin{array}{c}\text { Copper } \\
\text { Wire }\end{array}$ \\
\hline 1 & No & No-load rotation & $\bullet$ & $\bullet$ & $\bullet$ & $\bullet$ & $\bullet$ & $\bullet$ & & & & \\
\hline 2 & $\mathrm{IO}$ & No load current & $\bullet$ & $\bullet$ & $\bullet$ & $\bullet$ & $\bullet$ & $\bullet$ & & & & \\
\hline 3 & $\mathrm{Nr}$ & Number of fixed load rotations & $\bullet$ & $\bullet$ & $\bullet$ & $\bullet$ & $\bullet$ & $\bullet$ & & & & \\
\hline 4 & RI & Rated load current & $\bullet$ & $\bullet$ & $\bullet$ & $\bullet$ & $\bullet$ & $\bullet$ & & & & \\
\hline 5 & Is & Starting current & $\bullet$ & $\bullet$ & $\bullet$ & $\bullet$ & $\bullet$ & $\bullet$ & & & & \\
\hline 6 & Ts & Starting torque & $\bullet$ & $\bullet$ & $\bullet$ & $\bullet$ & $\bullet$ & $\bullet$ & & & & \\
\hline 7 & $\mathrm{Kt}$ & Torque constant & $\bullet$ & $\bullet$ & $\bullet$ & $\bullet$ & $\bullet$ & $\bullet$ & & & & \\
\hline 8 & To & Torque loss & & $\bullet$ & $\bullet$ & $\bullet$ & & & $\bullet$ & & & \\
\hline 9 & TouchR & TouchR & & & & & & & & $\bullet$ & $\bullet$ & \\
\hline 10 & IoUnst & wave motion & $\bullet$ & & & & & & & $\bullet$ & $\bullet$ & \\
\hline 11 & SurgeV & Surge voltage & $\bullet$ & & & & & & & $\bullet$ & $\bullet$ & \\
\hline 12 & Vibration & Flutter & $\bullet$ & & & & & & & $\bullet$ & $\bullet$ & \\
\hline 13 & StartV & Starting voltage & $\bullet$ & & & $\bullet$ & & & & $\bullet$ & $\bullet$ & \\
\hline 14 & InsuV & Insulation voltage & $\bullet$ & & & & & & & & & \\
\hline 38 OldNo & CoilR & Coil Resistance & & & & & & & & & $\bullet$ & $\bullet$ \\
\hline
\end{tabular}




\subsection{Statistical Analysis of the Case Results}

Case 1: The effect of the number of rotations on vibration, current fluctuation, and torque loss.

A complex regression analysis was used to evaluate the chatter vibration. Chatter vibration was found to increase with a higher number of no-load and fixed-load rotations per second. To establish whether the effects of the no-load or fixed-frame load rotation variables were statistically significant and whether one had more influence than the other, the $p$-values (i.e., significance) of their combined $9.7 \%$ variation were evaluated (Table 8). The combined $p$-value of the two variables was 0.000 (Table 9), indicating that at least one of the two variables had an effect on the vibration. Furthermore, the individual $p$-values of both variables were 0.000 , indicating that both variables had a significant and equivalent effect. The positive $t$-values were 6.679 for no-load rotation and 8.547 for fixed-load rotation, indicating that an increased number of no-load and fixed-load rotations led to increased chatter vibration.

Table 8. ANOVA ${ }^{\mathrm{a}}$-Multiple regression mutation of the number of rotations and vibrations.

\begin{tabular}{cccccc}
\hline Model & Sum of Squares & Degrees of Freedom & Mean Square Sum & F & $p$ \\
\hline Regression & $49,108,206.088$ & 2 & $24,554,103.044$ & 194.279 & $0.000^{\mathrm{b}}$ \\
Residual & $455,367,902.256$ & 3603 & $126,385.762$ & & \\
Total & $504,476,108.344$ & 3605 & & & \\
\hline
\end{tabular}

${ }^{a}$ Dependent variable: Vibration. ${ }^{\mathrm{b}}$ Predictive variable: (constant), Number of fixed-load rotation, No-load rotation.

Table 9. Coefficient ${ }^{\mathrm{a}}$-Complex regression coefficients for the number of rotations and vibrations.

\begin{tabular}{cccccccc}
\hline \multirow{2}{*}{ Model } & \multicolumn{2}{c}{$\begin{array}{c}\text { Unstandardized } \\
\text { Coefficient }\end{array}$} & $\begin{array}{c}\text { Normalization } \\
\text { Coefficient }\end{array}$ & t-Value & $p$-Value & \multicolumn{2}{c}{ Collinearity Statistics } \\
\cline { 2 - 8 } & $\begin{array}{c}\text { Estimated } \\
\text { Value of B }\end{array}$ & $\begin{array}{c}\text { Standard } \\
\text { Error }\end{array}$ & $\begin{array}{c}\text { Beta } \\
\text { Distribution }\end{array}$ & & & Tolerance & $\begin{array}{c}\text { Variance } \\
\text { Inflation Factor }\end{array}$ \\
\hline (constant) & -6836.050 & 462.102 & & -14.793 & 0.000 & & \\
No load rotation & 0.832 & 0.125 & 0.148 & 6.679 & 0.000 & 0.509 & 1.965 \\
Number of fixed & 0.691 & 0.081 & 0.190 & 8.547 & 0.000 & 0.509 & 1.965 \\
load rotations & & & & & & & \\
\hline
\end{tabular}

${ }^{a}$ Dependent variable: Vibration.

The relationship between the 3.1\% variation in current fluctuation and the number of no-load and fixed-load rotations was investigated using a complex regression analysis. The combined P-value of the two variables was 0.000 (Table 10), while the individual P-values were 0.041 for no-load rotation and 0.000 for fixed-load rotation (Table 11). This result shows that, although both variables were significant, the number of fixed-load rotations was more influential. The $t$-values were -2.049 for no-load rotation and 8.994 for fixed-load rotation. Therefore, an increased number of no-load rotations led to a decrease in current fluctuation, but an increased number of fixed-load rotations led to an increase in current fluctuation.

Table 10. ANOVA ${ }^{\text {a }}$-Multiple regression mutation of rotation count and current fluctuation.

\begin{tabular}{lccccc}
\hline Model & Sum of Squares & Degrees of Freedom & Mean Square Sum & F & $p$ \\
\hline Regression & 900.137 & 2 & 450.068 & 58.241 & $0.000^{\mathrm{b}}$ \\
Residual & $27,843.071$ & 3603 & 7.728 & & \\
Total & $28,743.208$ & 3605 & & \\
\hline a Dependent variable: Current fluctuation. ${ }^{\text {b }}$ Predictive variable: (constant), Number of fixed load rotations, \\
No load rotation.
\end{tabular}


Table 11. Coefficient ${ }^{\mathrm{a}}$-Complex regression coefficients for rotation number and current fluctuation.

\begin{tabular}{|c|c|c|c|c|c|c|c|}
\hline \multirow{2}{*}{ Model } & \multicolumn{2}{|c|}{$\begin{array}{l}\text { Unstandardized } \\
\text { Coefficient }\end{array}$} & \multirow{2}{*}{$\begin{array}{c}\begin{array}{c}\text { Normalization } \\
\text { Coefficient }\end{array} \\
\text { Beta } \\
\text { Distribution }\end{array}$} & \multirow{2}{*}{ t-Value } & \multirow{2}{*}{$p$-Value } & \multicolumn{2}{|c|}{ Collinearity Statistics } \\
\hline & $\begin{array}{l}\text { Estimated } \\
\text { Value of B }\end{array}$ & $\begin{array}{l}\text { Standard } \\
\text { Error }\end{array}$ & & & & Tolerance & $\begin{array}{c}\text { Variance } \\
\text { Inflation Factor }\end{array}$ \\
\hline (constant) & -11.750 & 3.613 & & -3.252 & 0.001 & & \\
\hline No load rotation & -0.002 & 0.001 & -0.047 & -2.049 & 0.041 & 0.509 & 1.965 \\
\hline $\begin{array}{l}\text { Number of fixed } \\
\text { load rotations }\end{array}$ & 0.006 & 0.001 & 0.207 & 8.994 & 0.000 & 0.509 & 1.965 \\
\hline
\end{tabular}

${ }^{a}$ Dependent variable: Current fluctuation.

The relationship between the $3.4 \%$ variation in torque loss and the number of no-load and fixed-load rotations was considered. The combined P-value of the two variables was 0.000 (Table 12), and the individual P-values of both variables were also 0.000 (Table 13), indicating that both variables had a significant and equivalent effect. The t-values were 10.678 for no-load rotation and 10.329 for fixed-load rotation. Therefore, an increased number of no-load rotations led to a decrease in torque loss, whereas an increased number of fixed-load rotations led to an increase in torque loss.

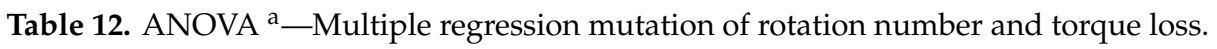

\begin{tabular}{cccccc}
\hline Model & Sum of Squares & Degrees of Freedom & Mean Square Sum & F & $p$ \\
\hline Regression & 24.866 & 2 & 12.433 & 64.962 & $0.000^{\mathrm{b}}$ \\
Residual & 689.560 & 3603 & 0.191 & & \\
Total & 714.426 & 3605 & & & \\
\hline
\end{tabular}

${ }^{a}$ Dependent variable: Torque loss. ${ }^{b}$ Predictive variable:(constant), Number of fixed load rotations, No load rotation.

Table 13. Coefficient ${ }^{\mathrm{a}}$-Multiple regression coefficients for rotation number and torque loss.

\begin{tabular}{|c|c|c|c|c|c|c|c|}
\hline \multirow{2}{*}{ Model } & \multicolumn{2}{|c|}{$\begin{array}{l}\text { Unstandardized } \\
\text { Coefficient }\end{array}$} & \multirow{2}{*}{$\begin{array}{c}\begin{array}{c}\text { Normalization } \\
\text { Coefficient }\end{array} \\
\text { Beta } \\
\text { Distribution }\end{array}$} & \multirow{2}{*}{ t-Value } & \multirow{2}{*}{$p$-Value } & \multicolumn{2}{|c|}{ Collinearity Statistics } \\
\hline & $\begin{array}{l}\text { Estimated } \\
\text { Value of B }\end{array}$ & $\begin{array}{l}\text { Standard } \\
\text { Error }\end{array}$ & & & & Tolerance & $\begin{array}{c}\text { Variance } \\
\text { Inflation Factor }\end{array}$ \\
\hline (constant) & 6.290 & 0.569 & & 11.062 & 0.000 & & \\
\hline No load rotation & -0.002 & 0.000 & -0.245 & -10.678 & 0.000 & 0.509 & 1.965 \\
\hline $\begin{array}{l}\text { Number of fixed } \\
\text { load rotations }\end{array}$ & 0.001 & 0.000 & 0.237 & 10.329 & 0.000 & 0.509 & 1.965 \\
\hline
\end{tabular}

${ }^{\text {a }}$ Dependent variable: Torque loss.

Case 2: The effect of current on surge voltage and coil resistance.

The relationship between the $1.6 \%$ variation in surge voltage and the no-load, fixed-load, and starting currents was investigated using a complex regression analysis. The combined $p$-value of the three variables was 0.000; thus, one or more variables had a significant effect on the surge voltage (Table 14). The individual $p$-values were $0.085,0.002$, and 0.000 for no-load current, fixed-load current, and starting current, respectively (Table 15). Thus, only the fixed-load and starting currents were considered significant, although the starting current was more influential. The t-values were 3.074 for the fixed-load current and -7.238 for the starting current. Therefore, an increase in fixed-load current led to an increase in surge voltage, but an increase in starting current led to a decrease in surge voltage. 


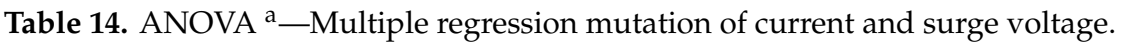

\begin{tabular}{cccccc}
\hline Model & Sum of Squares & Degrees of Freedom & Mean Square Sum & F & $p$ \\
\hline Regression & 146.777 & 3 & 48.926 & 20.440 & $0.000^{\mathrm{b}}$ \\
Residual & 8621.816 & 3602 & 2.394 & & \\
Total & 8768.594 & 3605 & & & \\
\hline
\end{tabular}

${ }^{a}$ Dependent variable: SurgeV. ${ }^{\text {b }}$ Predictive variable:(constant), Starting current, No load current, Rated load current.

Table 15. Coefficient ${ }^{\mathrm{a}}$-Complex regression coefficients for current and surge voltage.

\begin{tabular}{cccccccc}
\hline \multirow{3}{*}{ Model } & \multicolumn{2}{c}{$\begin{array}{c}\text { Unstandardized } \\
\text { Coefficient }\end{array}$} & $\begin{array}{c}\text { Normalization } \\
\text { Coefficient }\end{array}$ & t-Value & $p$-Value & \multicolumn{2}{c}{ Collinearity Statistics } \\
\cline { 2 - 8 } & $\begin{array}{c}\text { Estimated } \\
\text { Value of B }\end{array}$ & $\begin{array}{c}\text { Standard } \\
\text { Error }\end{array}$ & $\begin{array}{c}\text { Beta } \\
\text { Distribution }\end{array}$ & & & Tolerance & $\begin{array}{c}\text { Variance } \\
\text { Inflation Factor }\end{array}$ \\
\hline (constant) & 19.649 & 2.161 & & 9.094 & 0.000 & & \\
No load current & -0.013 & 0.007 & -0.096 & -1.721 & 0.085 & 0.087 & 11.434 \\
Rated load current & 0.019 & 0.006 & 0.173 & 3.074 & 0.002 & 0.086 & 11.650 \\
Starting current & -0.001 & 0.000 & -0.125 & -7.238 & 0.000 & 0.910 & 1.099 \\
\hline
\end{tabular}

${ }^{\mathrm{a}}$ Dependent variable: SurgeV.

The relationship between the $76.5 \%$ variation in coil resistance and the no-load, fixed-load, and starting currents was considered. The combined $p$-value was 0.000 (Table 16), while the individual $p$-values were $0.011,0.007$, and 0.000 for no-load current, fixed-load current, and starting current, respectively (Table 17). Thus, all three variables were significant, although the starting current was the most influential. The $t$-values were $2.546,-2.698$, and -102.806 for no-load current, fixed-load current, and starting current, respectively. Therefore, an increase in the no-load current led to increased coil resistance, but increased fixed-load and starting currents led to decreased coil resistance.

Table 16. ANOVA ${ }^{\text {a }}$-Multiple regression mutation of current and coil resistance.

\begin{tabular}{cccccc}
\hline Model & Sum of Squares & Degrees of Freedom & Mean Square Sum & F & $p$ \\
\hline Regression & 928.209 & 3 & 309.403 & 3905.135 & $0.000^{\mathrm{b}}$ \\
Residual & 285.386 & 3602 & 0.079 & & \\
Total & 1213.594 & 3605 & & & \\
\hline
\end{tabular}

${ }^{a}$ Dependent variable: CoilR. ${ }^{b}$ Predictive variable: (constant), Starting current, No load current, Rated load current.

Table 17. Coefficient ${ }^{\mathrm{a}}$-Complex regression coefficients for current and coil resistance.

\begin{tabular}{cccccccc}
\hline \multirow{2}{*}{ Model } & \multicolumn{2}{c}{$\begin{array}{c}\text { Unstandardized } \\
\text { Coefficient }\end{array}$} & $\begin{array}{c}\text { Normalization } \\
\text { Coefficient }\end{array}$ & $\mathbf{t}$-Value & $p$-Value & \multicolumn{2}{c}{ Collinearity Statistics } \\
\cline { 2 - 7 } & $\begin{array}{c}\text { Estimated } \\
\text { Value of B }\end{array}$ & $\begin{array}{c}\text { Standard } \\
\text { Error }\end{array}$ & $\begin{array}{c}\text { Beta } \\
\text { Distribution }\end{array}$ & & & Tolerance & $\begin{array}{c}\text { Variance } \\
\text { Inflation Factor }\end{array}$ \\
\hline (constant) & 13.070 & 0.393 & & 33.247 & 0.000 & & \\
No load current & 0.003 & 0.001 & 0.070 & 2.546 & 0.011 & 0.087 & 11.434 \\
Rated load current & -0.003 & 0.001 & -0.074 & -2.698 & 0.007 & 0.086 & 11.650 \\
Starting current & -0.003 & 0.000 & -0.871 & -102.806 & 0.000 & 0.910 & 1.099 \\
\hline
\end{tabular}

a Dependent variable: CoilR.

\subsection{Research Hypotheses}

Case 1: The effect of the number of rotations on vibration, current fluctuation, and torque loss.

The hypothesis that the number of no-load rotations affected the vibration, current fluctuation, and torque loss (H1) was confirmed. Furthermore, the no-load rotation was positively correlated with chatter vibration (H1-1) and inversely correlated with torque loss (H1-3), but was not positively correlated with current fluctuation (H1-2). 
The hypothesis that the number of fixed-load rotations affected the vibration, current fluctuation, and torque loss (H2) was confirmed. Furthermore, fixed-load rotation was positively correlated with vibration (H2-1) and current fluctuation ( $\mathrm{H} 2-2)$, but it was not inversely correlated with torque loss (H2-3).

Case 2: The effect of current on surge voltage and coil resistance.

The hypothesis that the no-load current affected the surge voltage and coil resistance was partially confirmed (H3), because no-load current affected the coil resistance but did not significantly affect the surge voltage. The no-load current was not positively correlated with the surge voltage (H3-1) and was also not inversely correlated with coil resistance (H3-2).

The hypothesis that the fixed-load current affected surge voltage and coil resistance $(\mathrm{H} 4)$ was confirmed. Furthermore, the fixed-load current was positively correlated with surge voltage (H4-1) and inversely correlated to coil resistance (H4-2).

The hypothesis that the starting current affected surge voltage and coil resistance (H5) was confirmed. Furthermore, the starting current was inversely correlated to coil resistance (H5-1), but was not positively correlated to surge voltage (H5-2).

See Table 18 for the research hypothesis test results.

Table 18. Validation of the hypotheses.

\begin{tabular}{lc}
\hline Case 1 & Outcome \\
\hline H1: The number of no-load rotations affects vibration, current fluctuation, and torque loss. & Confirmed \\
H1-1: The number of no-load rotations is positively correlated with vibration. & Confirmed \\
H1-2: The number of no-load rotations is positively correlated with the current fluctuation. & Rejected \\
H1-3: The number of no-load rotations is inversely correlated to torque loss. & Confirmed \\
H2: The number of fixed-load rotations affects vibration, current fluctuation, and torque loss. & Confirmed \\
H2-1: The number of fixed-load rotations is positively related to vibration. & Confirmed \\
H2-2: The number of fixed-load rotations is positively correlated to the current fluctuation. & Confirmed \\
H2-3: The number of fixed-load rotations is inversely correlated to torque loss. & Rejected \\
\hline Case 2 & Outcome \\
\hline H3: The no-load current affects surge voltage and coil resistance. & Partially confirmed \\
H3-1: The no-load current is positively correlated to surge voltage. & Rejected \\
H3-2: The no-load current is inversely correlated to coil resistance. & Rejected \\
H4: The fixed-load current affects surge voltage and coil resistance. & Confirmed \\
H4-1: The fixed-load current is positively correlated to surge voltage. & Confirmed \\
H4-2: The fixed-load current is inversely correlated with coil resistance. & Confirmed \\
H5: The starting current affects surge voltage and coil resistance. & Confirmed \\
H5-1: The starting current is positively correlated to surge voltage. & Rejected \\
H5-2: The starting current is inversely correlated to coil resistance. & Confirmed \\
\hline
\end{tabular}

Based on the validation results, there were five rejected hypotheses and several items in the manufacturing process that could indicate manufacturing errors. Through analysis, we could determine which parts lead to problems during assembly.

Flowcharts to support decision-making for problem identification are presented in Appendices A-D.

Based on the regression results, we established the following 5 relationships: (1) the no-load slewing number was positively correlated with vibration and negatively correlated with current fluctuation and torque loss; (2) the fixed-load rotation speed was positively correlated with vibration, current fluctuation, and torque loss; (3) the no-load current was positively correlated with coil resistance; (4) the fixed-load current was positively correlated with surge voltage and negatively correlated with coil resistance; and (5) the starting current was negatively correlated with the surge voltage and coil resistance. These relationships can be used to guide the investigations of manufacturing production staff. 
When the no-load slewing number is not within a standard range, the value of chatter vibration, current fluctuation, and torque loss should be evaluated (Appendix A). If the chatter vibration or current fluctuation value is outside the standard range, there is at least one error in the production process involving one of the following components: the coil, the terminal assembly, or the brush (Table 7). If the torque loss value is outside the standard range, the manufacturing of at least one of the following parts has failed: the iron frame, the iron frame lid, or the magnet. If the chatter vibration, current fluctuation, and torque loss are all normal, then the manufacturing of the bearing parts was faulty.

When the number of fixed-load rotations is outside the standard range, the value of vibration, current fluctuation, and torque loss should be evaluated (Appendix B). If there is an abnormality in the vibration or current fluctuation, there was at least one error in the production process of the components of the coil, terminal assembly, or brush (Table 7). If the torque loss value is abnormal, the manufacturing of at least one of the following parts failed: the iron frame, the iron frame lid, or the magnet. If the chatter vibration, current fluctuation, and torque loss are all normal, then the bearing parts are at fault.

An abnormal no-load current indicates that the coil resistance should be evaluated. If the coil resistance is abnormal, then the production of either the copper wire or brush parts was defective. If the coil resistance is normal, then the iron frame, iron frame lid, magnet, or bearing are faulty.

When the value of the rated load current is abnormal, the value of the surge voltage and the coil resistance should be evaluated. If the surge voltage is abnormal, at least one of the components in the coil, terminal assembly, or brush production process failed. If the coil resistance is abnormal, the copper wire or brush production process failed. If neither is abnormal, one of the following parts failed: the iron frame, the iron frame lid, the magnet, or the bearing.

According to the research results, when the starting current value is outside the standard range, the surge voltage and the coil resistance values should be evaluated. If the surge voltage is abnormal, at least one of the components in the coil, terminal assembly, or brush production process failed. If the coil resistance is abnormal, the copper wire or brush failed, and at least one part of the production process went wrong. If neither is abnormal, the production process for the iron frame, iron frame lid, magnet, or bearing failed.

\section{Discussion and Conclusions}

\subsection{Discussion}

This study explored motor production data to improve the efficiency of motor manufacturing processes. Data were analyzed and organized to effectively interpret the measurements of important motor performance indicators, including no-load rotations, fixed-load rotations, no-load current, fixed-load current, and starting current. These values can be used to evaluate the condition of a motor's operation, which encompasses the principles of mechanics, metal magnets, and electrical circuits. Furthermore, the interpretation of these parameters relies on fundamental wave propagation, power, voltage, and current theories.

The information on rotation and current parameters provided insight into vibrations, current fluctuations, torque loss, surge voltage, and coil resistance. This interpretation relied on linear regression with multiple independent variables. Dependent variables were also considered for a more robust discussion. Although some of the test hypotheses were not valid, the relationships between many of the parameters were demonstrated. Practical experts determined that the first-level data improved the production line's operational model.

The detected data were closely related to the condition of the products and thus provided an accurate representation of the production process. Since big data technology is based on data content, the association and impact of the data parameters were evaluated. In the production line, an abnormal no-load or fixed-load rotation reading is indicative of a change in vibration, current fluctuation, 
or torque loss. Similarly, an abnormal starting current is indicative of a change in coil resistance or surge voltage. If a parameter is not within a typical standard range, an error may occur throughout several production steps. A decision-making model may be developed based on the findings of this study, to avoid unnecessary costs and ensure smooth production operations. Human operators will be alerted to take corrective measures as soon as the first error occurs. For example, if the fixed-load current is abnormal, one should assess the surge voltage and the coil electric group (coil resistance). An abnormality in the coil electric unit shows that there is a problem with the brush components, thus narrowing the scope of the inspection. A swift response to address this brush assembly issue can ensure a quick return to an efficient and smooth motor production process. This targeted corrective process can save manpower and time, thereby allowing the Solen Electric Company to invest in production beyond motors.

The findings of this study echo the basic principles outlined by Mayr et al. [25], which detail how big data analysis and forecasting can be used to complement motor production line management. A wide variety of new technologies have been gradually adopted by the manufacturing industry. However, there is a large gap between the less sophisticated technologies currently used in Taiwan and the fully intelligent technologies available for production line automation. Furthermore, one should consider whether gold fees are allowed. A fundamental analysis of the data and related analytical techniques must be conducted, as these new technologies rely on a back-end database created via the continuous calculation of multiple data streams. Big data are a fundamental operating resource for many technologies [24], and this study investigated their application using production data to ultimately improve the motor production line. A decision-making model was also added to analyze the production process.

\subsection{Theoretical and Practical Implications}

The theoretical model was condensed from the original 88 detection parameters, which included 40 clockwise/counter-clockwise pairs, by only considering a counter-clockwise direction, thereby eliminating 40 parameters (Figure 3). The interviews with practical experts revealed that only 14 of the 48 remaining parameters should be considered. To determine the relationships between these parameters, the hypotheses were assessed using SPSS data analysis. These relationships highlighted which motor components affected the values of each parameter, thus revealing the failure points in the production process. These findings were important for the development of the decision-making model.

Big data are used as an important auxiliary tool in production, sales, investments, and many other fields. Regardless of the industry, these data can be used as a powerful decision-making and trend prediction tool. This study demonstrated that individual companies could benefit from using big data methods in motor production lines to integrate their production processes. Motor product testing data were used to map the production process and identify the points at which errors have previously occurred within specific components. While these mistakes can be corrected relatively easily, big data methods can also suggest production improvements to increase the company's competitiveness in the market, and encourage customers and other manufacturers to buy the company's products.

The analyzed company could not provide data for all of its production lines and has not fully automated its production, which is a characteristic of Industry 4.0. If funding allows, it is recommended that the company replace its manual operations and production processes (with the exception of skilled production processes) with machine-assisted or fully computerized automated production. The generated digital information will enable various successive departments to communicate along the production line. The findings of this study show that no impediments are expected between the initial stages and final assembly of the parts and components. This reduces the number of meetings, documents, and handwritten records associated with the production process, thus reducing space, time, and personnel requirements. The scope of this data method can also be widened to other processes.

Although some machines only allow unilateral automation, experts in the information field can supervise the development of a suitable information system for the output of production data. Big data 
can be complemented with other technologies, such as artificial intelligence, blockchain, and cloud applications, if the company establishes a foundation for implementing these technologies. The future development of more production line operation models shows great promise.

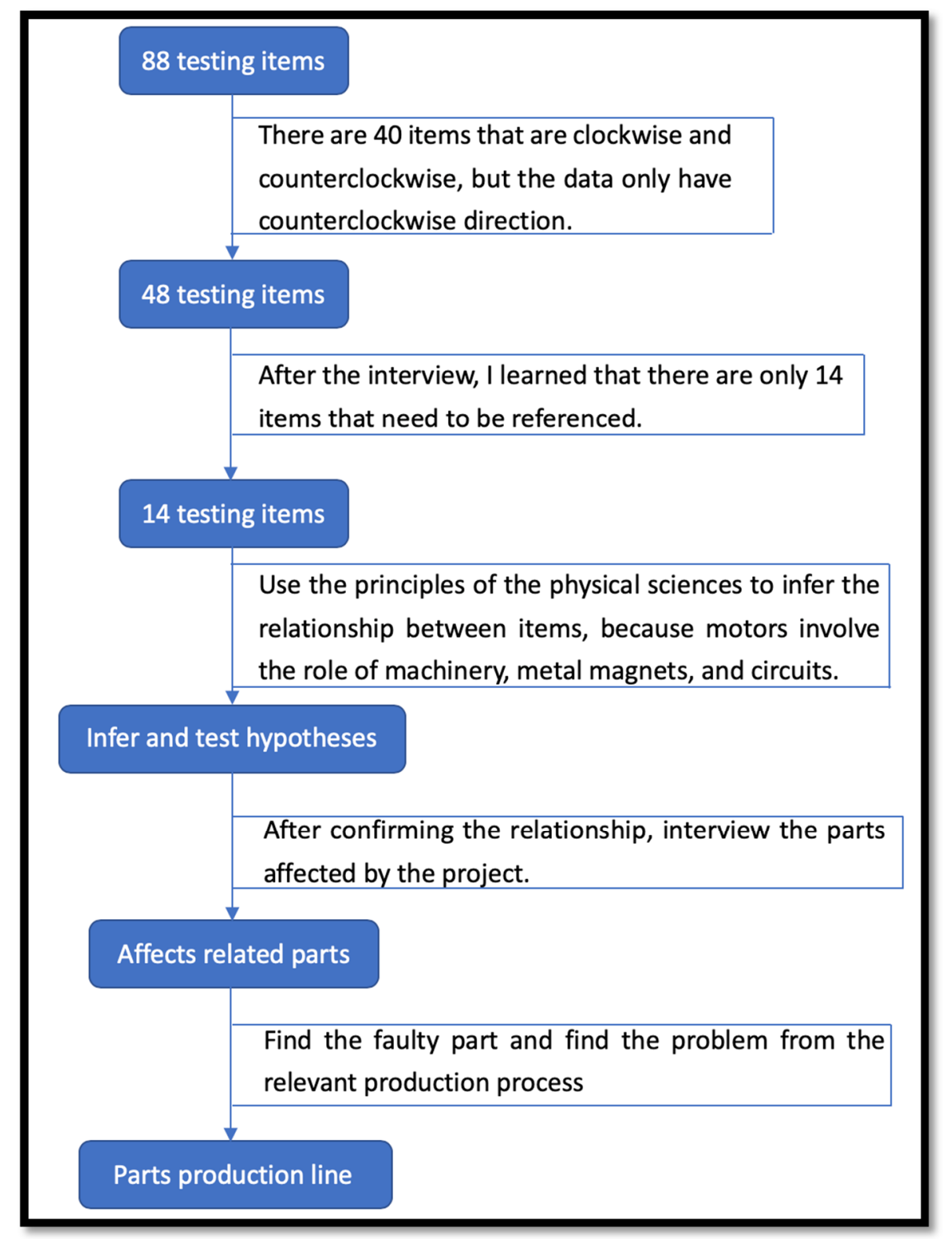

Figure 3. Research model based on the selection of testing parameters and their relation to specific motor components/parts.

\subsection{Conclusions and Further Recommendations}

This study implemented a big data analysis of intelligent manufacturing into traditional manufacturing motor production lines. Using tools such as SPSS and WEKA, 3606 records of the previous pilot production of Solen Electric Company's motor production lines were analyzed. Experts were interviewed to determine the three key points for improving the efficiency of the production line and the company's sustainable development. First, this study found that the key detection indicators in the motor production line are the no-load slewing number, fixed load slewing number, no-load current, fixed load current, starting current, starting torque, torque constant, torque loss, and brush contact. The 74 (of the 88 ) detection parameters from the original design were reduced to 
14 items (resulting in an $84.1 \%$ reduction). This reduction created a significant simplification of the quality control process and increased production line capacity. The final 14 key parameters, including resistance, current fluctuation, surge voltage, starting voltage, vibration, and insulation resistance, were measured. Second, this study analyzed a large amount of data through linear regression and the WEKA deep learning linear regression method, and found that when the value of the no-load current, fixed load current, or starting current is abnormal, the value will indirectly affect the data performance of coil resistance or surge voltage. The number of load revolutions or fixed-load revolutions will affect the vibration, current fluctuation, or torque loss value changes. In the future, if production line operators find that the aforementioned parameters deviate from the normal standard range, they can immediately determine or predict which production step is wrong and quickly correct it, thus making the motor production process more efficient. Finally, in the field of smart manufacturing, the big data ecosystem has six key driving forces: "data, forecasting, system integration, sustainability, resource sharing, and hardware." In addition, it also includes nine elements of the big data ecosystem: data extraction, storage, computing, analysis, visualization, management, workflow, infrastructure, and security enhancement. However, no big data solution was found for enterprises in the recent literature review [28]. A previous study observed that the correct use of real-time information will lead to the next industrial revolution, so the modern manufacturing industry must regard the modernization (digitalization) of the production process as the most important factor to achieve the goal of sustainable development [29]. This study is a practical study, proving that, after digitizing part of the production process and collecting complete records and storing data, the management mechanisms, such as expert experience and the use of analytical tools, will be enhanced. Future developments can help small and medium-sized traditional industries save manpower and increase profits. These results also indirectly prove that in the future of Industry 4.0, big data will become the key to the sustainable development of enterprises. Presently, Solen Electric Company's production lines in Taiwan and Vietnam are continuing to expand. The intelligent production of this motor production line was successfully affirmed by the OEM partner company, and a Shanghai factory (China) was contacted to inquire about new orders. It is expected that the amount of future data will increase exponentially. The academic definition of big data has become a model for small and medium-sized enterprises in developing countries, to develop smart manufacturing and industrial transformations.

According to the theoretical basis in [28], the research into big data solutions focuses on monitoring, forecasting, data analysis, and proposing solutions, which is consistent with the basic hypothesis of this study. The latest research [30] shows that the object of this study has gradually moved towards intelligent system processes. The results of this study determine that the intelligent process is correct and predictable. In terms of research implications, linear regression and machine learning, most results of the tests supported the research hypothesis. This research is focused on customer driven sustainable development, because big data requires that customers request their data to be collected, and every shipment must include data for all products, because a customer needs to confirm and track the quality of such products, to ensure the reliability of the end products that they manufacture [30]. This study found a link between Industry 4.0 and sustainability. The UN Sustainable Development Indicators related to this study are: Goal 9, Build resilient infrastructure, promote inclusive and sustainable industrialization, and foster innovation and Goal 12, Ensure sustainable consumption and production patterns. Goal 9.2 in this study, to promote inclusive and sustainable industrialization, refers to the impact of upgrading manufacturing to big data. Goal 9.4, upgrade infrastructure and retrofit industries to make them sustainable, refers to the combination of manufacturing process changes and the use of big data analysis to enhance production line automation. Finally, goal 12.A, support developing countries to strengthen their scientific and technological capacity, is related to the production line in this study, which is located in the developing country of Ho Chi Minh City, Vietnam. This study attempts to introduce the latest production technology into the combination of big data and Industry 4.0 , to assist the manufacturing capacity of developing countries. 
This study recommends several topics to guide future research in this field. Data and information related to other production processes are recommended to develop an improved understanding of the correlation between the data related to specific motor components and the finished motor products. Analytical software can be used to calculate the models for research, as a computer can automatically monitor the motor production data. This will allow for a more accurate prediction of the processes most commonly associated with problems. Big data analysis extends beyond the production of motors and can be used to improve the efficiency of various production lines, with notable application potential in medical equipment, sanitary equipment, and water valves.

\subsection{Study Limitations}

This study has several limitations that should be noted when interpreting the results. Product test data were used without considering the production line data of other related components. Most of the company's production processes were based on manual operation. As machines were operated by human operators, it was not possible to determine the precise values of these production processes, thereby affecting the integrity of the study's results. SPSS was used for data analysis because self-organizing algorithms and other sophisticated modeling approaches were not suitable for this application. If the nature of the dataset allowed for predictions on the production line or for the accurate identification of key production factors, the findings of this study would have been even more valuable and robust. Despite these limitations, this study is an important reference for future industry implementation and improvement.

Author Contributions: Y.-C.L., C.-C.Y., W.-H.C., W.-C.L., and J.-J.W. contributed equally to the research design and preparation of the manuscript. All authors have read and approved the final manuscript.

Funding: This research received no external funding.

Acknowledgments: This research was funded by the Taiwan Ministry of Science and Technology (MOST 108-2745-8-155-001). All authors are also appreciate Solen Electric Company to their support in research work and materials.

Conflicts of Interest: The authors have no conflicts to declare.

\section{Appendix A}

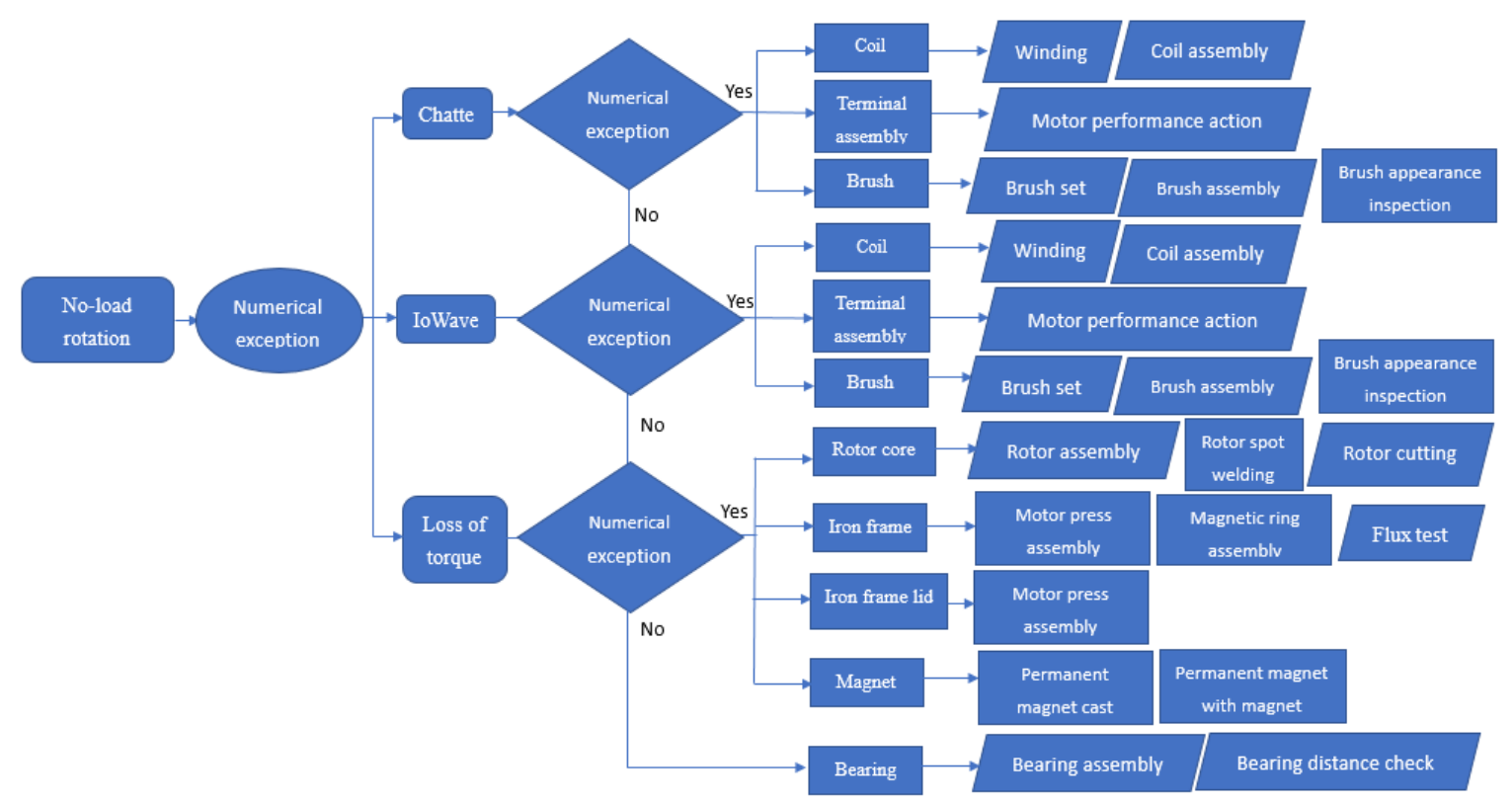




\section{Appendix B}

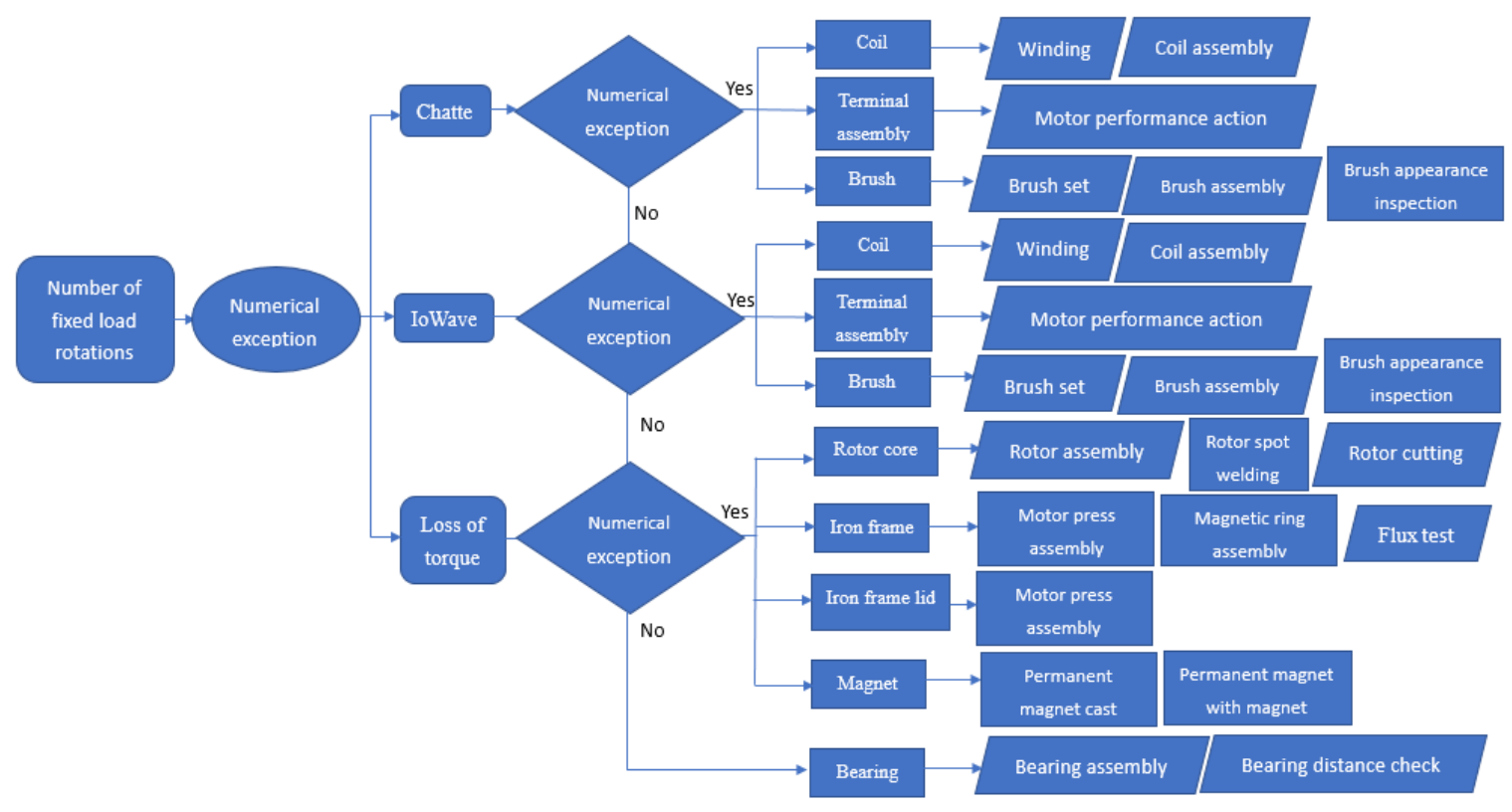

\section{Appendix C}

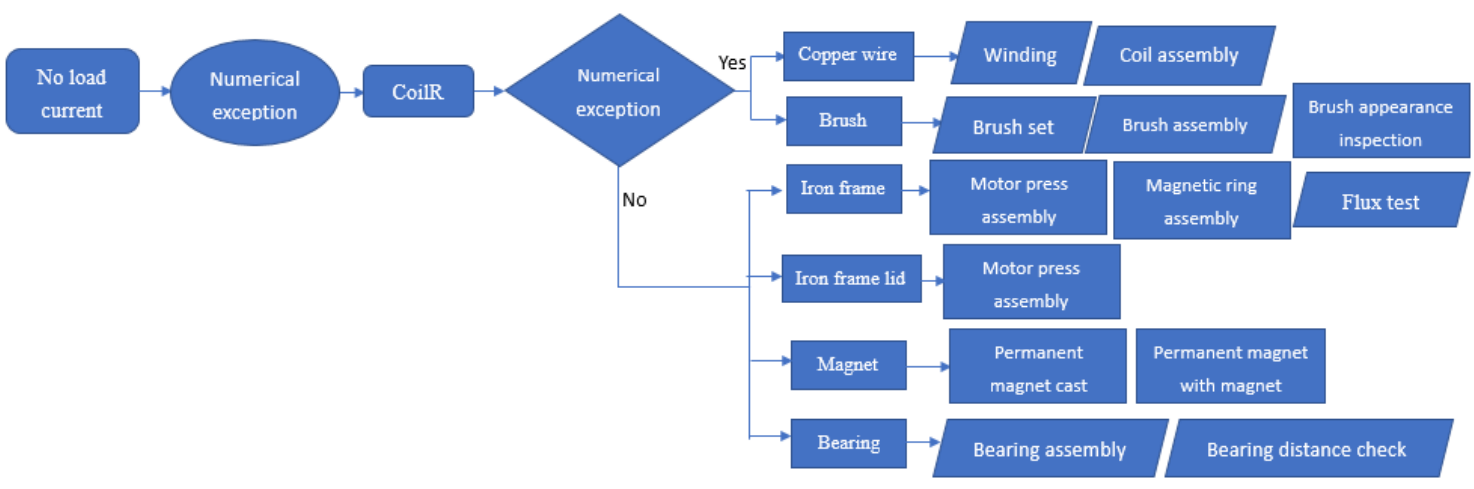

\section{Appendix D}

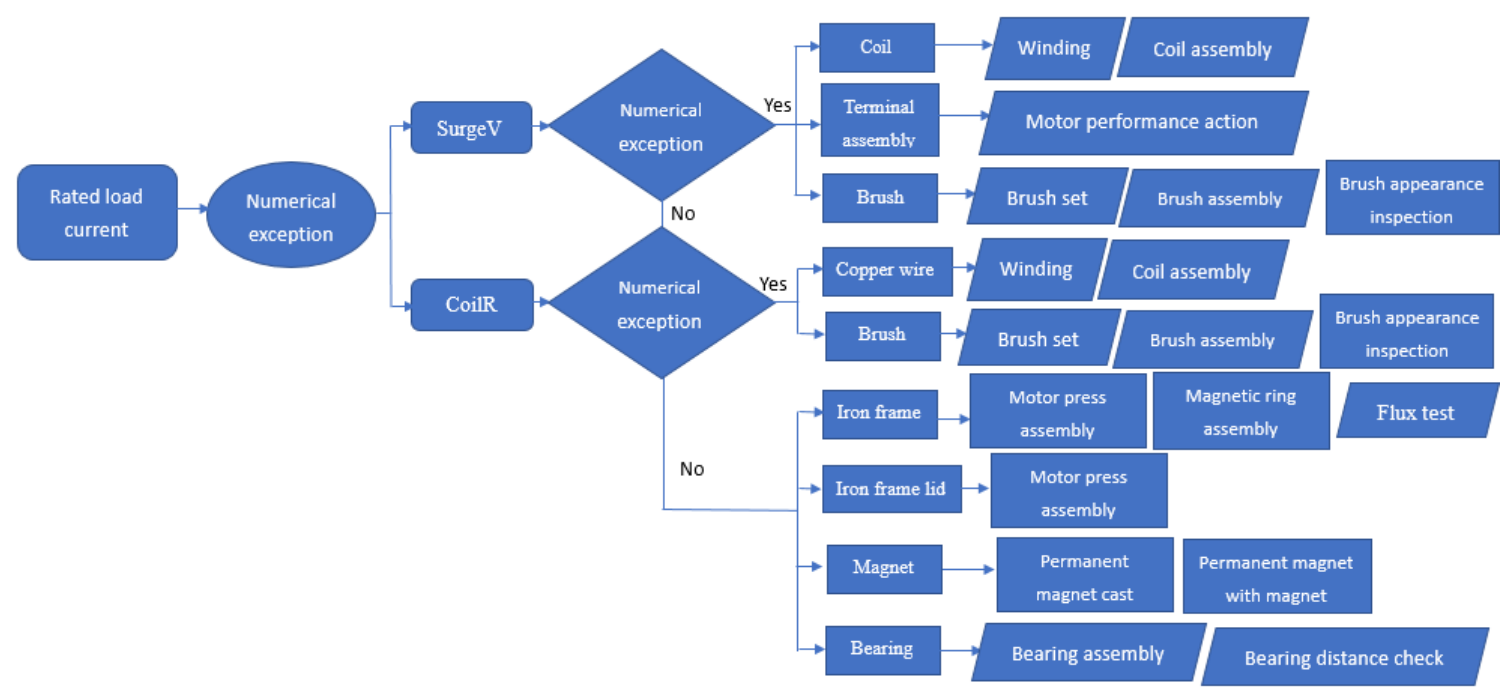




\section{Appendix E}

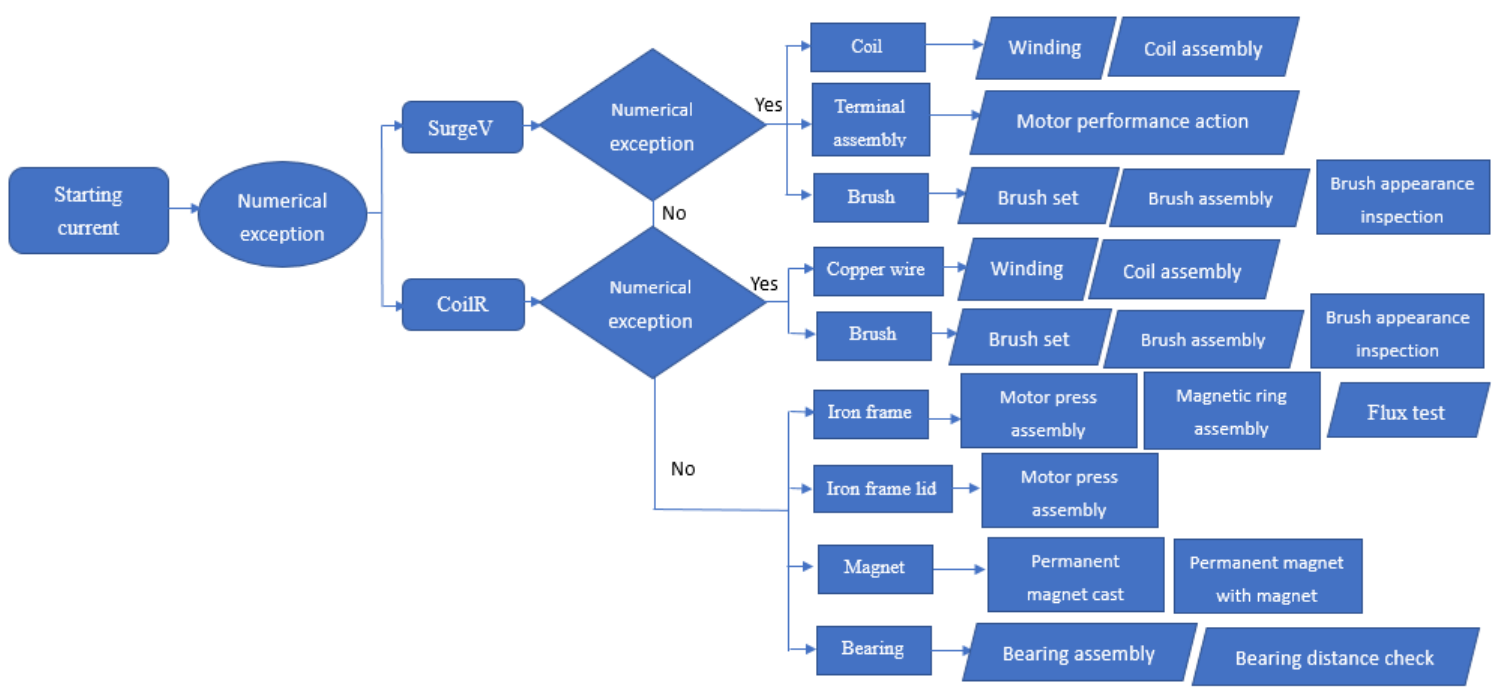

\section{References}

1. Liska, R. Management Challenges in the Digital Era. In Analyzing the Impacts of Industry 4.0 in Modern Business Environments; Brunet-Thornton, R., Martinez, F., Eds.; IGI Global: Hershey, PA, USA, 2018; pp. 82-99.

2. Shrouf, F.; Ordieres, J.; Miragliotta, G. Smart factories in Industry 4.0: A review of the concept and of energy management approached in production based on the Internet of Things paradigm. In Proceedings of the 2014 IEEE International Conference on Industrial Engineering and Engineering Management, Bandar Sunway, Malaysia, 9-12 December 2014; pp. 697-701.

3. Chen, G.; Wang, P.; Feng, B.; Li, Y.; Liu, D. The framework design of smart factory in discrete manufacturing industry based on cyber-physical system. Int. J. Comput. Integr. Manuf. 2020, 33, 79-101. [CrossRef]

4. IBM. Big Data Analysis of Manufacturing Industry to Create a New Generation of Smart Factories. 2015. Available online: https://www.cw.com.tw/article/article.action?id=5068696 (accessed on 20 November 2019).

5. Ren, S.; Zhang, Y.; Liu, Y.; Sakao, T.; Huisingh, D.; Almeida, C.M. A comprehensive review of big data analytics throughout product lifecycle to support sustainable smart manufacturing: A framework, challenges and future research directions. J. Clean. Prod. 2019, 210, 1343-1365. [CrossRef]

6. Matt, D.T.; Orzes, G.; Rauch, E.; Dallasega, P. Urban production-A socially sustainable factory concept to overcome shortcomings of qualified workers in smart SMEs. Comput. Ind. Eng. 2018, 105384. [CrossRef]

7. Moktadir, M.A.; Ali, S.M.; Kusi-Sarpong, S.; Shaikh, M.A.A. Assessing challenges for implementing Industry 4.0: Implications for process safety and environmental protection. Process Saf. Environ. Prot. 2018, 117, 730-741. [CrossRef]

8. Wang, B.; Wu, C. Safety informatics as a new, promising and sustainable area of safety science in the information age. J. Clean. Prod. 2020, 252, 119852. [CrossRef]

9. Ismail, A.; Truong, H.-L.; Kastner, W. Manufacturing process data analysis pipelines: A requirements analysis and survey. J. Big Data 2019, 6, 1. [CrossRef]

10. Fernández-Caramés, T.M.; Blanco-Novoa, O.; Froiz-Míguez, I.; Fraga-Lamas, P. Towards an Autonomous Industry 4.0 Warehouse: A UAV and Blockchain-Based System for Inventory and Traceability Applications in Big Data-Driven Supply Chain Management. Sensors 2019, 19, 2394. [CrossRef]

11. Columbus, Louis (Forbes). The Future of Manufacturing Technologies. 2018. Available online: https://www. forbes.com/sites/louiscolumbus/2018/04/15/the-future-of-manufacturing-technologies-2018/\#d7556f029955 (accessed on 1 February 2020).

12. Castelo-Branco, I.; Cruz-Jesus, F.; Oliveira, T. Assessing Industry 4.0 readiness in manufacturing: Evidence for the European Union. Comput. Ind. 2019, 107, 22-32. [CrossRef] 
13. Trend Micro. A Look into Smart Factories: A Model of IIoT Innovation. 2018. Available online: https://www.trendmicro.com/vinfo/ph/security/news/internet-of-things/a-look-into-smart-factoriesa-model-of-iiot-innovation (accessed on 22 October 2019).

14. Feng, J.; Li, F.; Xu, C.; Zhong, R.Y. Data-driven analysis for RFID-enabled smart factory: A case study. IEEE Trans. Syst. Man Cybern. Syst. 2018. [CrossRef]

15. Sim, H.S. Big data analysis methodology for smart manufacturing systems. Int. J. Precis. Eng. Manuf. 2019, 20, 973-982. [CrossRef]

16. Shivajee, V.; Singh, R.K.; Rastogi, S. Manufacturing conversion cost reduction using quality control tools and digitization of real-time data. J. Clean. Prod. 2019, 237, 117678. [CrossRef]

17. Deebak, B.; Al-Turjman, F. A hybrid secure routing and monitoring mechanism in IoT-based wireless sensor networks. Ad Hoc Netw. 2020, 97, 102022. [CrossRef]

18. Hwang, Y.J.; Jang, J.Y.; Song, S.; Kim, J.M.; Lee, S. Feasibility study of the impregnation of a no-insulation HTS coil using an electrically conductive epoxy. IEEE Trans. Appl. Supercond. 2017, 27, 1-5. [CrossRef]

19. Mohammed, A.; Melecio, J.I.; Djurović, S. Stator Winding Fault Thermal Signature Monitoring and Analysis by in situ FBG sensors. IEEE Trans. Ind. Electron. 2018, 66, 8082-8092. [CrossRef]

20. Faroukhi, A.Z.; El Alaoui, I.; Gahi, Y.; Amine, A. Big data monetization throughout Big Data Value Chain: A comprehensive review. J. Big Data 2020, 7, 1-22. [CrossRef]

21. Henke, N.; Bughin, J.; Chui, M.; Manyika, J.; Saleh, T.; Wiseman, B.; Sethupathy, G. The Age of Analytics: Competing in a Data-Driven World; McKinsey \& Company: San Francisco, CA, USA, 2016.

22. Bokrantz, J.; Skoogh, A.; Berlin, C.; Wuest, T.; Stahre, J. Smart Maintenance: An empirically grounded conceptualization. Int. J. Prod. Econ. 2019, 107534. [CrossRef]

23. Duan, Y.; Cao, G.; Edwards, J.S. Understanding the impact of business analytics on innovation. Eur. J. Oper. Res. 2020, 281, 673-686. [CrossRef]

24. Lin, R.; Xie, Z.; Hao, Y.; Wang, J. Improving high-tech enterprise innovation in big data environment: A combinative view of internal and external governance. Int. J. Inf. Manag. 2020, 50, 575-585. [CrossRef]

25. Mayr, A.; Weigelt, M.; von Lindenfels, J.; Seefried, J.; Ziegler, M.; Mahr, A.; Urban, N.; Kühl, A.; Hüttel, F.; Franke, J. Electric Motor Production 4.0-Application Potentials of Industry 4.0 Technologies in the Manufacturing of Electric Motors. In Proceedings of the 8th International Electric Drives Production Conference (EDPC, Schweinfurt, Germany, 4-5 December 2018; pp. 1-13.

26. Sapena-Bano, A.; Martinez-Roman, J.; Puche-Panadero, R.; Pineda-Sanchez, M.; Perez-Cruz, J.; Riera-Guasp, M. Induction machine model with space harmonics for the diagnosis of rotor eccentricity, based on the convolution theorem. Int. J. Electr. Power Energy Syst. 2020, 117, 105625. [CrossRef]

27. Witten, I.H.; Frank, E. Data Mining Practical Machine Learning Tools and Techniques, 2nd ed.; Morgan Kaufmann Publishers: San Francisco, CA, USA, 2005.

28. Cui, Y.; Kara, S.; Chan, K.C. Manufacturing big data ecosystem: A systematic literature review. Robot. Comput. Integr. Manuf. 2020, 101861. [CrossRef]

29. Oztemel, E.; Gursev, S. Literature review of Industry 4.0 and related technologies. J. Intell. Manuf. 2020, 31, 127-182. [CrossRef]

30. Lin, Y.-C.; Yeh, C.-C.; Chen, W.-H.; Hsu, K.-Y. Implementation Criteria for Intelligent Systems in Motor Production Line Process Management. Processes 2020, 8, 537. [CrossRef]

(C) 2020 by the authors. Licensee MDPI, Basel, Switzerland. This article is an open access article distributed under the terms and conditions of the Creative Commons Attribution (CC BY) license (http://creativecommons.org/licenses/by/4.0/). 